\title{
Environmental Concern Behaviours in Africa: An Exploratory Study
}

\author{
Adele Berndt ${ }^{1} \&$ Lucy Gikonyo ${ }^{2}$ \\ ${ }^{1}$ Jönköping International Business School, Jönköping, Sweden \\ ${ }^{2}$ Strathmore University, Nairobi, Kenya \\ Correspondence: Adele Berndt, Jönköping International Business School, P O Box 1026, Jönköping, SE551-11, \\ Sweden. E-mail: adele.berndt@jibs.hj.se
}

Received: February 9, 2012 Accepted: March 19, 2012 Online Published: May 24, 2012

doi:10.5539/jms.v2n2p1 URL: http://dx.doi.org/10.5539/jms.v2n2p1

\begin{abstract}
Environmental concern, including environmental behaviour continues to receive attention in both the public media and academic research. The purpose of the paper is to investigate environmental behaviour (both purchasing and non-purchasing behaviour) in an African context. Use was made of a quantitative study among a convenience sample of selected Africans. Statements reflecting non-purchasing behaviour indicated lower mean scores when compared to purchasing behaviour statements. Statistically significant differences were found to exist between different age groups with respect to both purchasing and non-purchasing behaviour as well as between different nationalities with regard to their purchasing behaviour. The findings have the potential of impacting the strategies of organisations operating on the continent. The major contribution of this paper is that is provides insight in the behavioural aspects as seen in an African context, and consequently provides detail on both purchasing and non-purchasing behaviour and the role of marketing aspects (such as price) in influencing purchase behaviour of Africans.
\end{abstract}

Keywords: environmental concern, purchase behaviour, non-purchase behaviour, Africa, environmental behaviour

\section{Introduction}

Environmental concern is a theme that is commonly found in the popular press, with many column inches dedicated to the specific threats facing mankind, and specific actions that will be required to change the current environmental situation. This interest in matters relating to the environment is not limited to the popular press but also receives attention in academic literature (Cronin et al., 2011). Studies relating to the environment are not limited to any specific subject discipline, indicating the interest of many researchers in this area (Diamantopolous et al., 2003; Kilbourne \& Beckman, 1998). Studies have been carried out at the macro-level (in examining the nature of environmental problem) but in the case of marketing, the focus has tended to be on the micro or individual level (Kilbourne \& Beckman, 1998).

Environmental concern is not only important to organisations, but is something that consumers evaluate when making decisions (Diamantopolous et al., 2003). The consequence of the consumer decision-making process is action (Schiffman et al., 2008), thus behaviour is an important manifestation of environmental concern (Stern, 2000). It has been suggested that $87 \%$ of US adults are concerned about the environment and these concerns are reflected on the product purchase decisions made (Prakash, 2002; Schlegelmilch et al., 1996). Environmental behaviours can be focused specifically on purchasing activities (such as what is purchased and the packaging associated with the item purchased) as well as non-purchasing activities (such as support for environmental organisations).

Research has indicated that environmental behaviours are carried out by many different groups of people, motivated by different factors (Corraliza \& Berenguer, 2000; Fraj \& Martinez, 2006; Kok \& Siero, 1985; Oskamp et al., 1991; Van Liere \& Dunlap, 1978; Vining \& Ebreo, 1990). Studies have investigated the various factors influencing specific environmental behaviours. Differences between groups involved in environmental behaviour (specifically focused on recycling) have been found in a number of different areas including knowledge (Vining \& Ebreo, 1990) demographic factors such as income and gender (Vining \& Ebreo, 1990), and the knowledge of the importance of recycling as an activity (Vining \& Ebreo 1990). Other studies have attempted to investigate the role of attitudes on environmental behaviour, with conflicting results (Barr, 2007; 
Grob, 1995; Guagnano et al., 1995). Yet other studies have investigated the role of values in environmental concern (Dunlap et al., 2000; Karp, 1996). Schlegelmilch et al., (1996) suggest that there is a weak link between attitudes and action when it comes to environmental issues. From these and similar studies, it appears that there is a 'disconnect between environmental attitudes ... and behaviours' (Cronin et al., 2011, p. 159).

While behaviours are an important part of environmental concern, there appears to be a lack of awareness of these behaviours in many developing economies, specifically on the African continent. South Africa and Kenya were selected for investigation due to their strategic role in the continent, specifically within their various regions of the continent. Little research has been published associated with the continent, and by investigating the purchasing and non-purchasing behaviour in African countries, organisations can develop appropriate strategies in targeting consumers and encouraging environmentally-conscious behaviour and adapt their marketing instruments accordingly.

Initially the paper will investigate the underlying aspects associated with environmental behaviours and then report on the specific study conducted and the findings as they related to organisations and communities marketing products and services in Africa.

\section{Research Objectives}

It has been suggested that environmental concern has a number of components, including an awareness component, an attitudinal component and a behavioural component (Bohlen et al., 1993). The reason for these components is that an individual needs to understand the environmental issue for a concern to develop, and this is reflected in attitudes and subsequent behaviours. The purpose of the research was to determine the environmental behaviours in emerging economies among selected African residents.

The primary objective of the research was thus to determine the actions of Africans with regards to environment issues. The secondary objectives of the research were to determine the following:

- $\quad$ The purchasing-specific behaviour in selected areas of Africa

- $\quad$ The non-purchasing behaviour in selected areas in Africa

\section{Literature Review}

\subsection{The Nature of Environmental Behaviour}

Environmental behaviour is regarded as the total actions exhibited towards the improvement of environmental quality. These behaviours are recognised as important due to the effect that the consequences of not acting in an environmentally-conscious way on the environment (Barr, 2007; Stern, 2000). For example, not recycling plastic items (i.e. not being environmentally-conscious) will have future impacts on society and on quality of life. This has resulted in development of recycling and waste reduction programmes in various communities (Schahn \& Holzer, 1990; Vining \& Ebreo, 1990). Many people are prepared to commit to improving the environment, but in general, people "actually do very fairly little and know even less" (McGuiness et al., 1977, p. 376).

\subsection{Approaches to Environmental Behaviour}

There are a number of approaches to classifying environmental behaviour. These approaches examine not only the actual behaviour but also the broader rationale for the behaviour.

\subsubsection{The Waste Management Hierarchy}

From a behavioural perspective, behaviour can be classified according to the specific actions which are exhibited with regard to waste items. It has been suggested that there is a waste management hierarchy, which is arranged from those behaviours that are the least environmentally-friendly to those that are more environmentally-friendly. The goal is thus to move up the waste hierarchy (Bates \& Phillips, 1998) and in so doing, move away from the use of landfills.

Waste reduction is where an individual tries to reduce the amount of waste generated and includes behaviours such as switching off lights when not in the room, thus it encourages individuals to use less of a specific item (Barr, 2007). It has been suggested this is becoming more important due to the problems associated with disposal of waste (Cronin et al., 2011). Reuse of items, such as glass and other reusable items where the item does not form waste, but is rather useful. Recovery involves harvesting energy from waste and examples of these include recycling, composting and the "recovery of energy from waste" and it may include converting the waste into other products or be reused in manufacturing (Barr, 2007). Disposal is necessary when the item is placed in a landfill or incinerated, and is regarded as the least attractive option. 


\subsubsection{Intent- and Impact-orientated Behaviours}

Consumers engage in environmental behaviours in order to have an impact on the environment. Stern (2000) classifies environmental concern behaviour into intent-orientated and impact-orientated behaviour, where intent-orientated behaviour has the aim to change the environment, usually to the benefit of the environment (Stern, 2000). The intent-orientated view focuses on the beliefs and motives so as to understand and change target behaviours among customers (Stern, 2000). In this instance, customer intention is part of the decision-making process. Impact-orientated behaviour investigates environmental behaviour based on the outcome of the behaviour on the environment (Stern, 2000). Behaviour (specifically associated with an impact-orientation perspective) includes environmental activism, non-activist behaviour in a public sphere, private-sphere environmentalism and other environmentally-significant behaviours (Stern, 2000). The impact of a specific behaviour can be differentiated from the intention that is associated with behaviour. By buying a specific product, the consumer may intend not to harm the environment but still cause environmental damage.

\subsubsection{Purchasing and Non-purchasing Behaviours}

Bohlen et al (1993) classify environmental behaviour as purchasing and non-purchase related. Purchasing behaviour that reflects environmental concern is linked to the purchase of environmentally-friendly products as well as the evaluation of products in the purchasing situation. It is suggested that a belief that the consumer's behaviour can affect the environment provides motivation when making product purchasing decisions (Cronin et al., 2011). Non-purchasing behaviour includes other actions that are taken in the area of environmental awareness, such as encouraging others to recycle. Specifically, two categories of non-purchasing behaviour have been identified namely, political and recycling activities (Schlegelmilch et al., 1996). Bohlen et al (1993, p. 418) suggest that those who are "environmentally-sensitive to an extreme" are those who would be prepared to engage in political actions.

\subsection{Theories of Environmental Behaviour}

Various theories have been used to propose how environmental concern behaviour comes about.

The $A B C$ theory proposed by Guagnano et al., (1995) suggests that behaviour is a product of attitude variables and contextual factors. Their model attempts to reflect how attitudes and contextual factors affect whether (or not) behaviour will result. Pro-environmental behaviours are affected by personal commitment and the perceived personal costs as well as benefits associated with specific actions (Stern, 2000). Non-environmental attitudes can also affect environmental behaviour, such as views about speed and power (Stern, 2000). Contextual factors refer to those aspects in the broader environment (such as the social norms and politics) and include the interpersonal influences, political and other community expectations as well as monetary incentives offered. An example of a contextual factor includes the cost of organic foods, which are higher than non-organic foods. These contextual factors range from negative to positive. Behaviour results when contextual factors and attitudes tend to being positive. Should these factors be negative, behaviour will not result.

The Theory of reasoned action of Fishbein and Ajzen attempts to show the relationship between attitudes and actions, and behavioural intention is a consequence of attitudes and social norms (Kok \& Siero, 1985). It also suggests that knowledge (awareness) of environmental issues should result in environmentally-responsible behaviour (Schahn \& Holzer, 1990). Previous research has not revealed any significant relationships/correlations between knowledge and self-reported behaviour (Schahn \& Holzer, 1990) though some studies have identified some weak correlations (Schahn \& Holzer, 1990).

Schwartz's norm activation theory suggests that the likelihood of recycling increases when an individual is aware of the harmful consequences of the environment, combined with a sense of personal responsibility to impact the environmental condition (Stern et al., 2005; Kok \& Siero, 1985). The social norm affects the personal norm which impacts recycling behaviour. This behaviour is thus driven by a personal norm, such as altruism, and this in turn has effect on both environmental attitudes and actions such as recycling (Stern et al., 2005; Vining \& Ebreo, 1990). Hopper and Nielsen (1991) suggest that recycling reflects altruism, and that the altruism model is appropriate when examining recycling behaviour. In the case of recycling, behaviour can be regarded as altruistic, as the customer invests time and effort to advantage someone else (either the recycler or the organisation itself) without receiving any kind of compensation. For engaging in this behaviour, the consumer experiences a number of intrinsic benefits. These include a feeling of impacting on the environment for the 'common good' of society (Hopper \& Nielsen, 1991; Huge Brodin \& Anderson, 2008), as well as the ability of future generations to enjoy the environment. 
From the theories mentioned above, the role of attitudes, knowledge and contextual factors in environmental behaviour can be identified as some of the key drivers of behaviour.

\section{Hypothesis Development}

Based on the literature, there are a number of hypotheses that were formulated for the study. Diamontopolous et al., (2003) have summarised studies that investigate the effect of socio-demographic factors on the environmental consciousness (awareness, attitudes and actions) of people. Their research indicates that there are mixed results when attempting to link demographics to these aspects. In the case of environmental behaviour, Table 1 summarises the effect of various demographic factors on environmental behaviour. What can be seen in the summary is that no published studies have been undertaken among Africans regarding their environmental behaviour.

Table 1. Summary of the effect of socio-demographics on environmental behaviour

\begin{tabular}{|c|c|c|c|}
\hline $\begin{array}{l}\text { Socio-demographic } \\
\text { factor }\end{array}$ & $\begin{array}{l}\text { Number of } \\
\text { studies }\end{array}$ & $\begin{array}{l}\text { Location of } \\
\text { studies }\end{array}$ & Findings of studies \\
\hline Age & 27 & $\begin{array}{l}\text { UK, USA, Europe } \\
\text { and Israel }\end{array}$ & $\begin{array}{l}14 \text { studies indicated a positive effect on } \\
\text { environmental behaviour, } 5 \text { showed a negative } \\
\text { effect, } 12 \text { showed no significance of age on } \\
\text { behaviour. }\end{array}$ \\
\hline Gender & 26 & $\begin{array}{l}\text { UK, USA, Europe } \\
\text { and Israel }\end{array}$ & $\begin{array}{l}13 \text { studies indicated a positive effect on } \\
\text { environmental behaviour; } 11 \text { yield results that did } \\
\text { not show significance; } 1 \text { showed negative effect } \\
\text { while } 1 \text { study found a positive effect on purchasing } \\
\text { behaviour. }\end{array}$ \\
\hline
\end{tabular}

There have been conflicting findings regarding the role of demographic factors in environmental behaviours. It has been suggested that females are more likely to engage in environmental behaviour than men and that they are likely to do so more frequently (Diamantopolous et al., 2003). In the case of age, studies have reported different findings, depending on whether the researchers are investigating current behaviour or behavioural intentions. Some studies have found that older people are more likely to be involved in environmental behaviours due to the income level of this age group. In this study, nationality and employment status were additional socio-demographics that were included.

Hypothesis 1: Demographic factors (age, gender, employment status and nationality) impact the purchasing behaviour associated with environmental concern.

Hypothesis 2: Demographic factors (age, gender, employment status and nationality) impact the non-purchasing behaviour associated with environmental concern.

In this study, statements of both purchasing and non-purchasing behaviour have been used as suggested in previous studies (Bohlen et al., 1993). Factor analysis conducted by Bohlen et al., (1993) on the non-purchasing behaviour statements identified two factors, recycling and political action. However, as can be seen in Table 1, these studies have predominantly been undertaken in the UK, USA and Europe. This raises the questions as to the relevance of the statements in the African context. Thus:

Hypothesis 3: Selected African country data will yield the same dimensions of environmental behaviour, as suggested in previous studies.

\section{Research Methodology}

Use was made of a quantitative methodology in this research, with fieldworkers assisting in collecting data from respondents. Specifically, the research was descriptive in nature, with the aim to conduct an initial exploration of the actions exhibited with regards to environmental issues.

The target population of the study was residents of selected African counties. The sample used was a convenience sample of 450 respondents. The survey was administered with use of fieldworkers. 
The research instrument consisted of two sections, namely a demographic section and a section that investigated both purchasing and non-purchasing behaviour. The statements were linked to the studies conducted by Schlegelmilch et al., (1996), Bohlen et al., (1993), Vining and Ebreo (1990) and Maloney, Ward and Braucht (1975), and contained statements that related to both purchase and non-purchasing behaviour. The scale used was a five-point unlabelled Likert response format (where $1=$ never and $5=$ always).

\section{Findings of the Research}

\subsection{Reliability of the Action Statements}

Reliability of the measurement set measuring attitude towards environmental concern was measured using Cronbach's alpha or the coefficient alpha technique. A value of less than 0.7 typically indicates a low level of internal reliability (Hair et al., 2006) yet a Cronbach's alpha exceeding 0.6 is regarded as satisfactory. The reliability of the statements is reflected in Table 2.

Table 2. Reliability of statements

\begin{tabular}{llll}
\hline Dimension & Number of items & Cronbach Alpha & Reliability \\
\hline Total behaviour & 13 & 0.823 & High reliability \\
Purchasing behaviour & 8 & 0.744 & Acceptable reliability \\
Non-purchasing behaviour & 5 & 0.644 & Satisfactory reliability \\
\hline
\end{tabular}

\subsection{Respondent Profile}

The questionnaires were distributed among residents of Nairobi and Johannesburg. Various demographic variables were collected about the respondents, and a total of 450 responses were analysed. With regards to the age of the respondents, the majority (77.3\%) were in their 20s. Regarding their gender, $\mathbf{5 6 . 2 \%}$ were female. With respect to their employment, the majority $(\mathbf{7 5 . 3 \% )}$ ) were students, which is consistent with the age of the respondents. A total of $\mathbf{4 6 . 5 \%}$ of the respondents indicated their nationality as Kenyan. The profile is reflected in Table 3.

Table 3. Respondent profile

\begin{tabular}{ll}
\hline Characteristic & Distribution among respondents \\
\hline Age & $16.4 \%$ younger than $20 ; \mathbf{7 7 . 3} \%$ in their $20 \mathrm{~s} ; 5.2 \%$ in their $30 \mathrm{~s}$ and $1.1 \%$ in their $40 \mathrm{~s}$ \\
Gender & $43.8 \%$ male; $\mathbf{5 6 . 2} \%$ female \\
Employment status & $8.0 \%$ were employed on a full-time basis; $8.0 \%$ part time; $\mathbf{7 5 . 3 \%}$ were students and \\
& $8.6 \%$ unemployed \\
Nationality & $\mathbf{4 6 . 5 \%}$ Kenyan; $17.8 \%$ Motswana; $12.9 \%$ Zimbabwe; $13.6 \%$ South Africa; $3.1 \%$ \\
& Zambia; $1.5 \%$ Nigeria; $4.6 \%$ other nationalities \\
\hline
\end{tabular}

\subsection{Descriptive Analysis of the Statements Regarding Behaviour}

For each statement, a mean and a standard deviation was calculated. The statements that indicated purchasing behaviour were used to determine a mean purchasing behaviour score. The same methodology was used to determine a mean non-purchasing behaviour score. From Table 4, it can be seen that the mean purchasing score was 3.36, with a standard deviation of $\mathbf{0 . 7 6 4}$. The statement that has the highest mean score (as well as the lowest standard deviation) was the statement where respondents indicated that they would purchase an environmentally-friendly alternative of a similar price, if available (mean $=\mathbf{4 . 0 9}$; $\mathrm{SD}=\mathbf{1 . 0 8 7}$ ). This appears to support previous research which reflects customer resistance to paying higher prices for products that are regarded as "more environmentally friendly" (Prakash, 2002). In the case of the non-purchasing behaviour, the mean score was 2.96 and the standard deviation was $\mathbf{0 . 8 3 0}$. The statement (among the non-purchasing behaviour) with the highest mean referred to the taking of shopping bags when going shopping (rather than buying additional bags) (mean $=3.69$; $\mathrm{SD}=1.262$ ). The detail on each statement is found in Table 4 . 
Table 4. Descriptive statistics on the statements

\begin{tabular}{llc}
\hline Statement & Mean & $\begin{array}{c}\text { Standard } \\
\text { Deviation }\end{array}$ \\
\hline Buying behaviours & & \\
I choose an environmentally-friendly alternative if one of a similar price is & $\mathbf{4 . 0 9}$ & $\mathbf{1 . 0 8 7}$ \\
available & & \\
I choose environmentally-friendly products regardless of the price & 3.44 & 1.249 \\
I have changed to products that are environmentally-friendly & 2.34 & 1.282 \\
I try to buy environmentally-friendly detergents and cleaning materials & 3.21 & 1.241 \\
I buy products that have not been tested on animals & 3.81 & 1.345 \\
I prefer to buy recycled paper products & 3.74 & 1.360 \\
When possible, I prefer to buy organically grown fruit and vegetables & 3.94 & 1.180 \\
I make a special effort to buy products in recyclable containers & 2.35 & 1.451 \\
$\quad$ Mean buying behaviour score & $\mathbf{3 . 3 6}$ & $\mathbf{0 . 7 6 4}$ \\
Non-purchasing behaviours & & \\
I boycott organisations that are not environmentally responsible & 2.46 & 1.380 \\
I would join an environmental group to protect the environment & 2.69 & 1.390 \\
I try to find out about the environmental effects of a product before I buy it & 2.91 & 1.203 \\
I encourage other people to recycle & 3.05 & 1.286 \\
I take shopping bags when doing grocery shopping & $\mathbf{3 . 6 9}$ & $\mathbf{1 . 2 6 2}$ \\
$\quad$ Mean non-buying score & $\mathbf{2 . 9 6}$ & $\mathbf{0 . 8 3 0}$ \\
\hline
\end{tabular}

\section{Hypothesis Testing}

Prior to the analysis, the ages were grouped into three (Group 1: younger than 20; Group 2: 20 - 29 years; Group 3: 30 years and older).

Hypothesis 1: Demographic factors (age, gender, employment status and nationality) impact the purchasing behaviour associated with environmental concern.

H1A: There are significant differences in the purchasing behaviour of respondents of different age groups.

A one-way ANOVA was conducted to investigate the effect of age on environmental purchasing behaviour. Statistically significant differences were identified between the groups at the $95 \%$ confidence interval using a Brown-Forsyth test $(\mathrm{p}=0.009)$. Despite statistical significance, calculation of the effect size (eta squared) indicated a small effect size (0.02). Post-hoc comparisons using the Tukey HSD indicated that the mean score for Group $1(\mathrm{M}=3.14$; $\mathrm{SD}=0.863)$ was significantly different from Group $2(\mathrm{M}=3.39 ; \mathrm{SD}=0.752)$ and Group 3 $(\mathrm{M}=3.63 ; \mathrm{SD}=0.515)$. Group 2 did not differ significantly from Group 3. These findings suggest that those younger than 20 differ significantly in their purchase behaviour from older respondents. Thus the research hypothesis is accepted.

H1B: There are significant differences in the purchasing behaviour of male and female respondents.

An independent samples t-test was conducted to compare the purchasing behaviour for the genders. There were no significant differences between males $(\mathrm{M}=3.31 ; \mathrm{SD}=0.801)$ and females $(\mathrm{M}=3.40 ; \mathrm{SD}=0.738), t(391)=$ $-1.165, p=0.245$. Further, the effect size is very small $(r=0.00)$. From these findings, the hypothesis is not accepted.

H1C: There are significant differences in the purchasing behaviour based upon the employment status of respondents.

Due to the percentage of respondents who indicated their employment status as "students", three groups were formed. Group 1 comprised students, Group 2 was those who were employed and Groups 3 was those who were 
retired or unemployed. A one-way ANOVA was conducted to investigate the effect of employment status on environmental purchasing behaviour. No statistically significant differences were identified between employment status and purchasing behaviour among the various groups (Group 1: $\mathrm{M}=3.39$; $\mathrm{SD}=0.858$; Group 2: $\mathrm{M}=3.35$; $\mathrm{SD}=0.742$; Group 3: $\mathrm{M}=3.43$; $\mathrm{SD}=0.813 ; \mathrm{p}=0.653$ ). From these findings, the hypothesis is not accepted.

H1D: There are significant differences in the purchasing behaviour of respondents with different nationalities.

Prior to analysis, six distinct nationality groups were formed, namely South Africans, Motswana, Zimbabwe, Zambia, Kenya and other nationalities. Due to the violation of the homogeneity of variance, use was made of Browne-Forsythe test. Statistically significant differences at the $95 \%$ confidence interval were identified between the nationalities with respect to purchase behaviour $(\mathrm{F}(5,396) 11.169, \mathrm{p}=0.000)$. The effect size, calculated using eta squared, was 0.12 which is regarded as relatively large. Post-hoc comparisons using the Tukey HSD test indicated that the mean score of Group 5 (Kenyans; $\mathrm{M}=3.60$; $\mathrm{SD}=0.468$ ) differed from Group 1 (South Africans; $\mathrm{M}=3.16$; $\mathrm{SD}=0.947$ ), Group 2 (Zimbabweans; $\mathrm{M}=3.09$; $\mathrm{SD}=0.809$ ) and Group 3 (Zambians; $\mathrm{M}=3.20$; $\mathrm{SD}=1.180$ ). Thus the research hypothesis is accepted.

Hypothesis 2: Demographic factors (age, gender, employment status and nationality) impact the non-purchasing behaviour associated with environmental concern.

H2A: There are differences between the ages of the respondent and non-purchasing behaviour.

A one-way ANOVA was conducted to investigate the effect of age on environmental purchasing behaviour. Statistically significant differences were identified between the groups at the $95 \%$ confidence interval $(F(2,406)$ 5.761, $\mathrm{p}=0.003)$. Post-hoc comparisons using the Tukey HSD indicated that the mean score for Group $1(\mathrm{M}=2.64$; $\mathrm{SD}=0.794)$ was significantly different from Group $2(\mathrm{M}=3.00$; $\mathrm{SD}=0.833)$ and Group $3(\mathrm{M}=3.12$; $\mathrm{SD}=0.753)$. Group 2 did not differ significantly from Group 3. This means that this hypothesis is accepted.

H2B: There are differences between the genders of the respondent and non-purchasing behaviour.

An independent samples t-test was conducted to compare the purchasing behaviour for the genders. There were no significant differences between males $(\mathrm{M}=2.95 ; \mathrm{SD}=0.834)$ and females $(\mathrm{M}=2.95 ; \mathrm{SD}=0.832), t(408)=-.063$, $\mathrm{p}=0.950$. From these findings, the hypothesis is not accepted.

H2C: There are differences between the employment status of the respondents and non-purchasing behaviour.

A one-way ANOVA was conducted to investigate the effect of employment status on environmental purchasing behaviour. No statistically significant differences were identified between the employment status of the respondent and the non-purchasing behaviour shown (Group 1: $\mathrm{M}=2.99$; $\mathrm{SD}=0.871$; Group 2: $\mathrm{M}=2.91$; $\mathrm{SD}=0.814$; Group 3: $\mathrm{M}=3.24$; $\mathrm{SD}=0.836 ; \mathrm{p}=0.724$ ). From these findings, the hypothesis is not accepted.

H2D: There are differences between the nationality of the respondents and non-purchasing behaviour.

Prior to analysis, six distinct nationality groups were formed, namely South Africans, Motswana, Zimbabwe, Zambia, Kenya and other nationalities. No statistically significant differences at the $95 \%$ confidence interval were indicated ( $\mathrm{p}=0.189)$. From these findings, the hypothesis is not accepted.

Hypothesis 3: Selected African country data will yield the same dimensions of environmental behaviour, as suggested in previous studies.

To confirm that these statements are relevant in the African context, a factor analysis was conducted. Prior to conducting factor analysis, the correlation matrix was evaluated and many statements above 0.3 were found. Further, a Kaiser-Meyer-Olkin value of 0.877 indicated that the data were suitable for factor analysis. Use was made of Principal components analysis, and two factors were revealed. The two factors accounted for $55.014 \%$ of responses. The eigen values are reflected in Table 5.

Table 5. Eigen values associated

\begin{tabular}{lll}
\hline Factor & \% of variation & Cumulative $\%$ \\
\hline 1 & 33.935 & 33.935 \\
2 & 21.078 & 55.014 \\
\hline
\end{tabular}


Factor 1 consisted of 8 statements, of which 6 were purchasing statements. Factor 2 consisted of 5 statements, of which 3 statements were associated with non-purchasing behaviour. These factors were thus not renamed. The factors appear in Table 6.

Table 6. Factor analysis

\begin{tabular}{lll}
\hline & $\begin{array}{l}\text { Factor 1 } \\
\text { Purchasing } \\
\text { behaviour }\end{array}$ & $\begin{array}{l}\text { Factor } 2 \\
\text { Non-purchasing } \\
\text { behaviour }\end{array}$ \\
\hline $\begin{array}{l}\text { I prefer to buy recycled paper products } \\
\text { I buy products that have not been tested on animals }\end{array}$ & 0.840 \\
I choose environmentally-friendly products regardless of the price & 0.775 & 0.732 \\
I choose an environmentally-friendly alternative if one of a similar & 0.722 \\
price is available & & \\
I take shopping bags when doing grocery shopping & 0.648 & \\
I try to buy environmentally-friendly detergents and cleaning & 0.636 & \\
materials & & \\
I try to find out about the environmental effects of a product & 0.620 & \\
before I buy it & & \\
When possible, I prefer to buy organically grown fruit and & 0.585 & \\
vegetables & & 0.847 \\
I make a special effort to buy products in recyclable containers & & 0.837 \\
I have changed to products that are environmentally-friendly & & 0.805 \\
I would join an environmental group to protect the environment & & 0.597 \\
I boycott organisations that are not environmentally responsible & & 0.564 \\
I encourage other people to recycle & & \\
\hline
\end{tabular}

While there are minor differences on the factor loadings in the African continent, two factors can be identified, resulting in the acceptance of this hypothesis.

\section{Discussion}

The purpose of the research was to investigate the environmental behaviour of selected Africans, as it relates to both purchasing and non-purchasing actions. The research was able to access citizens of selected African countries, thereby determining the behaviour on a wider basis.

With regard to purchasing behaviour, the research shows that there are differences between ages and purchasing behaviour, with statistically significant differences between respondents younger than 20 and other respondents in both their purchasing and non-purchasing behaviour. No significant differences were found between the genders for the various types of employment status with respect to either type of behaviour. Statistically significant differences were found between the nationalities in the case of purchasing behaviour but not in the case of non-purchasing behaviour. These statistical differences are summarised in Table 7.

Table 7. Summary of hypotheses

\begin{tabular}{lll}
\hline & Purchasing behavior & Non-purchasing behavior \\
\hline Age & $\mathrm{p}=0.009$ & $\mathrm{p}=0.003$ \\
Gender & $\mathrm{p}=0.245$ & $\mathrm{p}=0.950$ \\
Employment status & $\mathrm{p}=0.653$ & $\mathrm{p}=0.724$ \\
Nationality & $\mathrm{p}=0.000$ & $\mathrm{p}=0.189$ \\
\hline
\end{tabular}


Managerial findings that accrue from this research are that the role of price in the purchasing behaviour respondents can be seen. If an environmentally-friendly alternative of the same price is available, respondents indicated a more positive response than if the price were higher. Organisations thus need to understand the price sensitivity of respondents as well as the trade-off between the price of the product and the environmental concern of the consumer. The findings also suggest that, in an African context, the youth view environmental issues differently from older consumers, and thus using this as a focus in both product development and marketing communication (as examples) is something that needs to be implemented. This is not restricted to only product-related (and hence purchasing- related behaviours) but includes involvement in other activities. In the case of national differences, care needs to be taken by specifically multinational organisations regarding the development of their marketing strategies in countries such as Kenya. These citizens have been shown to be different in terms of their environmental awareness, which should be integrated into marketing activities.

Limitations of this research can be identified as use was made of a convenience sample of these selected African countries. This impacts the extent to which the findings of the research can be generalised. There were also a high number of respondents who were in their 20s, and who indicated their employment status as that of students. This also impacts the extent to which the findings can be generalised to the broader population. Kenyan respondents dominated the research (from a nationality perspective), which creates the opportunity to expand the research into other African countries.

Future research includes expanding the research to include more nationalities and countries as well as investigating the awareness and attitudes in these countries, as well as determining the role of environmental and contextual factors in their behaviour.

\section{Conclusion}

Literature suggests that environmental behaviour is affected by various factors, including attitudes, awareness and environmental factors. The purpose of this research was to investigate the purchasing and non-purchasing behaviour among residents of various African countries. This was done using a quantitative methodology, and the study has shown statistically significant differences between younger Africans in their purchase and non-purchase behaviour as well as significant differences between nationalities among Africans with regard to their purchase behaviour. This shows potential for organisations and specifically their marketing strategies which will find resonance with consumers, which in turn will benefit other residents of the continent as well as the improved management of resources.

\section{References}

Barr, S. (2007). Factors influencing Environmental Attitudes and Behaviors: A UK Case Study of Household Waste Management. Environment and Behavior, 39(4), 435-473. http://dx.doi.org/10.1177/0013916505283421

Bates, M. P., \& Phillips, P. S. (1998). Waste minimisation in the food and drink industry. Nutrition and Food Science, 6, 330-334. http://dx.doi.org/10.1108/00346659810235260

Bohlen, G., Schlegelmilch, B. B., \& Diamantopoulos, A. (1993). Measuring Ecological Concern: A Multi-construct Perspective, Journal of Marketing Management, 9, 415-430. http://dx.doi.org/10.1080/0267257X.1993.9964250

Corraliza, J. A., \& Berenguer, J. (2000). Environmental Values, Beliefs and Actions: A Situational Approach. Environment and Behavior, 32, 832-848. http://dx.doi.org/10.1177/00139160021972829

Cronin, J. J., Smith, J. S., Gleim, M. R., Ramirez, E., \& Martinez, J. D. (2011). Green marketing strategies: an examination of stakeholders and the opportunities they present. Journal of the Academy of Marketing Science, 39, 158-174. http://dx.doi.org/10.1007/s11747-010-0227-0

Diamantopolous, A., Schlegelmilch, B. B., Sincovics, R. R., \& Bohlen, G. M. (2003). Can socio-demographics still play a role in profiling green consumers? A review of the evidence and an empirical investigation. Journal of Business Research, 56, 465-480. http://dx.doi.org/10.1016/S0148-2963(01)00241-7

Dunlap, R., Van Liere, K. D., Mertig, A. G., \& Jones, R. E. (2000). Measuring Endorsement of the New Ecological Paradigm: A Revised NEP Scale. Journal of Social Issues, 56(3), 425-442. http://dx.doi.org/10.1111/0022-4537.00176

Fraj, E., \& Martinez, E. (2006). Environmental values and lifestyles as determining factors of ecological consumer behaviour: an empirical analysis. Journal of Consumer Behaviour, 23(3), 133-144. 
Grob, A. (1995). A Structural Model of Environmental Attitudes and Behaviour. Journal of Environmental Psychology, 15, 209-220. http://dx.doi.org/10.1016/0272-4944(95)90004-7

Guagnano, G. A., Stern, P. C., \& Dietz, T. (1995). Influences on Attitude-Behavior Relationships: A Natural Experiment with Curbside Recycling. Environment and Behavior, 27(5), 699-718. http://dx.doi.org/10.1177/0013916595275005

Hair, J., Bush, R., \& Ortinau, D. (2006). Marketing Research within a changing environment (Revised international edition). New York, McGraw-Hill.

Hopper, J. R., \& Nielsen, J. M. (1991). Recycling as Altruistic Behaviour: Normative and Behavioural Strategies to Expad Participation in a Community Recycling Programme. Environment and Behavior, 23 (2), 195-220. http://dx.doi.org/10.1177/0013916591232004

Huge Brodin, M., \& Anderson, H. (2008). Recycling calls for revaluation. Supply Chain Management: An International Journal, 13(1), 9-15.

Karp, D. G. (1996). Values and their effect on Pro-Environmental Behaviour. Environment and Behaviour, 28(1), 111-133. http://dx.doi.org/10.1177/0013916596281006

Kilbourne, W.E., \& Beckman, S. C. (1998). Review and Critical Assessment of Research on Marketing and the

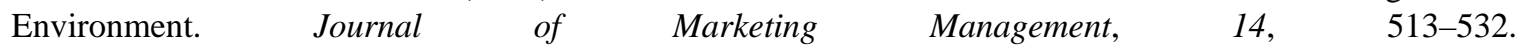
http://dx.doi.org/10.1362/026725798784867716

Kok, G., \& Siero, S. (1985). Tin recycling: Awareness, Comprehension, Attitude, Intention and Behaviour. Journal of Economic Psychology, 6, 157-173. http://dx.doi.org/10.1016/0167-4870(85)90019-4

Maloney, M. P., Ward, M. P., \& Braucht, G. N. (1975). A Revised Scale for the Measurement of Ecological Attitudes and Knowledge. American Psychologist, July, 787-790. http://dx.doi.org/10.1037/h0084394

McGuiness, J., Jones, A. P., \& Cole, S. G. (1977). Attitudinal Correlates of Recycling Behaviour. Journal of Applied Psychology, 62, 376-384. http://dx.doi.org/10.1037/0021-9010.62.4.376

Oskamp, S., Harrington, M. J., Edwards, T. C., Sherwood, D. L., Okuda, S. M., \& Swanson, D. C. (1991). Factors influencing household recycling behaviour. Environment and Behavior, 23(4), 494-519. http://dx.doi.org/10.1177/0013916591234005

Prakash, A. (2002). Green Marketing, public policy and managerial strategies. Business Strategy and the Environment, 11, 285-297. http://dx.doi.org/10.1002/bse.338

Schahn, J., \& Holzer, E. (1990). Studies of Individual Environmental Concern: The Role of Knowledge, Gender and Background Variables, Environment and Behavior, 22(6), 767-786. http://dx.doi.org/10.1177/0013916590226003

Schiffman, L., Bednall, D., O’Cass, A., Paladino, A., Ward, S., \& Kanuk, L. (2008). Consumer Behaviour (4th ed.). Australia: Pearson Education.

Schlegelmilch, B. B., Bohlen, G. M., \& Diamontopolous, A. (1996). The link between green purchasing decisions and measures of environmental consciousness. European Journal of Marketing, 30(5), 35-55. http://dx.doi.org/10.1108/03090569610118740

Stern, P. (2000). Towards a Coherent Theory of Environmentally Significant Behaviour. Journal of Social Issues, 56(3), 407-424. http://dx.doi.org/10.1111/0022-4537.00175

Stern, P. C., Dietz, T., \& Kalof, L. (2005). Value Orientations, Gender and Environmental Concern. In Kalof, L., \& Salterfield, T. (Eds.), Environmental Values. London: Earthscan.

Van Liere, K. D., \& Dunlap, R. E. (1978). Moral Norms and Environmental Behavior: An Application of Schwartz's Norm-Activation Model to Yard Burning. Journal of Applied Social Psychology, 8(2), 174-188. http://dx.doi.org/10.1111/j.1559-1816.1978.tb00775.x

Vining, J., \& Ebreo, A. (1990). What makes a recycler? A Comparison of Recyclers and Nonrecyclers. Environment and Behavior, 22(1), 55-73. http://dx.doi.org/10.1177/0013916590221003 